\title{
Quercetin modulates Nrf2 and glutathione-related defenses in HepG2 cells. Involvement of p38
}

Ana Belén Granado-Serrano, María Angeles Martín, Laura Bravo, Luis Goya and Sonia Ramos*

Department of Metabolism and Nutrition

Institute of Food Science, Technology and Nutrition-ICTAN (former Instituto del Frío)

Consejo Superior de Investigaciones Científicas (CSIC)

José Antonio Novais 10

Ciudad Universitaria, 28040, Madrid

Spain

Phone: +34.91 .544 .56 .07$

Fax: +34.91 .549 .36 .27$

* Corresponding author: e-mail: s.ramos@if.csic.es 


\section{Abstract ${ }^{1}$}

Dietary flavonoid quercetin has been suggested as a cancer chemopreventive agent, but the mechanisms of action remain unclear. This study investigated the influence of quercetin on p38MAPK and the potential regulation of the nuclear transcription factor erythroid-2p45-related factor (Nrf2) and the cellular antioxidant/detoxifying defense system related to glutathione (GSH) by p38 in HepG2 cells. Incubation of HepG2 cell with quercetin at a range of concentrations $(5-50 \mu \mathrm{M})$ for 4 or $18 \mathrm{~h}$ induced a differential effect on the modulation of p38 and Nrf2 in HepG2 cells, showing $50 \mu \mathrm{M}$ quercetin the highest activation of $\mathrm{p} 38$ and values similar to those of control cells after 4 and $18 \mathrm{~h}$ treatment, respectively, together with the inhibition of Nrf2 at both incubation times. Quercetin $(50 \mu \mathrm{M})$ induced a time-dependent activation of $\mathrm{p} 38$, which was in concert with a transient stimulation of Nrf2 to provoke its inhibition afterward. Quercetin also increased GSH content, mRNA levels of glutamylcysteine-synthetase (GCS) and expression and/or activity of glutathioneperoxidase, glutathione-reductase and GCS after 4h of incubation, and glutathione-S-transferase after $18 \mathrm{~h}$ of exposure. Further studies with the p38 specific inhibitor SB203580 showed that the p38 blockage restored the inhibited Nrf2 transcription factor and the enzymatic expression and activity of antioxidant/detoxificant enzymes after $4 \mathrm{~h}$ exposure. In conclusion, p38-MAPK is involved in the

\footnotetext{
1 Abbreviations used: AKT/PKB, protein kinase B; AP-1, activator protein-1; ARE, antioxidant response element; CHX, cycloheximide; DAPI, 6-diamidino-2-phenylindole; DTT, dithiothreitol; ERK, extracellular regulated kinase; FBS, fetal bovine serum; GAPDH, glyceraldehyde-3-phosphate dehydrogenase; GCS, glutamylcysteine synthetase; GPx, glutathione peroxidase; GR, glutathione reductase; GRB2, growth factor receptor-bound protein 2; GSH, glutathione; GST, glutathione S-transferase; JNK, c-jun amino-terminal kinase; Keap-1, Kelch-like ECH-associated protein-1; MAPK, mitogen-activated protein kinase; MCB, monochlorobimane; NAC, $N$-acetyl-cysteine; Nrf2, nuclear transcription factor erythroid 2p45 (NF-E2)-related factor; PARP, poly(ADPribose)polymerase; PI3K, phosphatidylinositol-3-kinase; PKC, protein kinase C; PMSF, phenylmethylsulfonyl fluoride; ROS, reactive oxygen species.
} 
mechanisms of the cell response to quercetin through the modulation of Nrf2 and glutathionerelated enzymes in HepG2 cells.

Keywords: Glutathione, Glutathione-related enzymes, Nrf2, p38, Quercetin. 


\section{Introduction}

Quercetin (3, 3', 4', 5, 7-pentahydroxylflavone) is a flavonoid, one of the most abundant polyphenolic groups in plants (fruits and vegetables) [1], which can be extensively metabolized during absorption in the small intestine and in the liver [2, 3]. Many studies have demonstrated that quercetin exerts potential anticarcinogenic activities, since it is a potent inhibitor of tumor initiation in vivo [4], is a powerful radical scavenger able to prevent or delay conditions which favor cellular oxidative stress $[5,6]$, possesses anti-proliferative activities against tumor cells in vitro $[4,7,8]$, and induces apoptosis in different cancer cell lines by modulating a number of key elements in cellular signal transduction pathways linked to the apoptotic cell death [1, 7-12].

Two possible mechanisms have been suggested to explain the chemoprotective effects of quercetin. The first includes the removal of preinitiated cells from damaged tissues through cell cycle arrest and apoptosis [10-13]. Alternatively, the modulation of metabolizing enzymes has been proposed as another chemopreventive mechanism that can block carcinogen activation (inhibition of cytochrome P450) or enhance the detoxification of activated carcinogens (activation of phase II detoxifying enzymes) [14]. Thus, quercetin is found to interact with the cellular defense system such as NADPH:quinone oxidoreductase, iNOS, monooxygenase, COX, xanthine oxidase, lipoxygenase, hemeoxygenase-1, etc. [8, 15-17]. In this regard, the induction of antioxidant/detoxifying enzymes as well as glutathione (GSH) levels provides significant biological mechanisms for protection against toxic effects of endogenous reactive oxygen species (ROS) and exogenous carcinogens and/or their reactive intermediates [16, 18-22].

Nuclear factor-erythroid 2p45-related factor-2 (Nrf2) plays a central role in the induction of antioxidant and detoxifying enzymes through its binding to the antioxidant response element (ARE) $[23,24]$. Nrf2 is sequestered in the cytoplasm as an inactive complex with its cytosolic repressor Kelch-like ECH associated protein-1 (Keap-1). The dissociation of Nrf2 from Keap-1 is crucial for 
its nuclear translocation, followed by binding to DNA and activation of cytoprotective genes [23]. To date, multiple signaling kinases related to cell survival/proliferation have been reported to regulate Nrf2, which include extracellular signal-regulated kinase (ERK), c-jun NH2-terminal kinase (JNK), phosphoinositide 3-kinase (PI3K) and protein kinase C (PKC) [21, 23]. Indeed, the phosphorylation of Nrf2 by these different kinases at multiple sites seems to be an important mechanism in Nrf2-mediated ARE activation and in regulating the stability of this transcription factor [25], but few data have been reported about Nrf2 regulation and p38 MAPK. p38 MAPK consists of four isoforms: $\mathrm{p} 38 \alpha, \mathrm{p} 38 \beta, \mathrm{p} 38 \gamma$ and $\mathrm{p} 38 \delta$. p38 $\alpha$ is the most abundant and ubiquitously expressed family protein and has a well established role in stress response and inflammation [26]. Once p38-MAPK is phosphorylated and activated, it phosphorylates and/or activates downstream substrates (kinases, transcriptional factors, etc.), resulting in various cellular responses such as proliferation, apoptosis, cell cycle arrest, and inflammation [26]. In line with this, up-regulation of the hemeoxygenase-1 detoxification enzyme via Nrf2 has been reported to involve p38-MAPK in renal cells [27]. Similarly, Yao et al [17] have demonstrated that p38 and ERK mediated quercetin-derived Nrf2 translocation into nuclei and subsequent induction of hemeoxygenase-1 activity.

Although different studies have consistently demonstrated that quercetin is a strong inducer of GSH content and antioxidant/detoxificant enzymes, the detailed upstream signaling mechanisms are still unclear. In the present study, quercetin modulation of p38 in relation to Nrf2 function and the role of p38 on the regulation of cellular antioxidant/detoxifying defense system related to glutathione have been analyzed. 


\section{Materials and methods}

\subsection{Materials and chemicals}

Quercetin, SB203580, cycloheximide (CHX), gentamicin, penicillin G and streptomycin were purchased from Sigma Chemical (Madrid, Spain). Anti-phospho-p38 recognizing phosphorylated Thr180/Tyr182 (9216) and anti- $\beta$-actin (4697) were obtained from Cell Signalling Technology (Izasa, Madrid, Spain). Anti-p38 a (sc-535), anti-Nrf2 (C-20, sc-722), anti-Nrf2 (H-300, sc-13032), anti-PARP (sc-7150) and anti-GRB2 (sc-255) were purchased from Santa Cruz Biotechnology Inc. (Santa Cruz, CA, USA). Materials and chemicals for electrophoresis were from BioRad (BioRad Laboratories S.A., Madrid, Spain). Cell culture dishes and cell culture medium were from Falcon (Cajal, Madrid, Spain) and Biowhittaker Europe (Lonza, Madrid, Spain), respectively.

\subsection{Cell culture and quercetin treatment}

Human hepatoma HepG2 cells were grown in DMEM F-12 medium from Biowhitaker (Lonza, Madrid, Spain), supplemented with 2.5\% Biowhitaker fetal bovine serum (FBS) and the following antibiotics: gentamicin, penicillin and streptomycin $(50 \mathrm{mg} / \mathrm{L})$. Cells were maintained at $37^{\circ} \mathrm{C}$ in a humidified atmosphere of $5 \% \mathrm{CO}_{2}$.

Cells were seeded and routinely grown in DMEM-F12 medium and 2.5\% FBS, but they were changed to serum-free medium $24 \mathrm{~h}$ before the assay in order to avoid the influence of the growth factors contained in the FBS on the results. To study the time-course effects of quercetin, cells were treated with $50 \mu \mathrm{M}$ quercetin and then harvested at different times $(0,10,30,60,120,240$ and 1080 $\min$ ).

In the experiments with quercetin and the selective pharmacological inhibitor of $\mathrm{p} 38$, cells were preincubated with SB203580 $(10 \mu \mathrm{M})$ for $2 \mathrm{~h}$ prior to $50 \mu \mathrm{M}$ quercetin treatment for $240 \mathrm{~min}$ or $1080 \mathrm{~min}$. 
To analyze the effect of quercetin and p38 inhibition on Nrf2 stabilization, HepG2 cells were incubated with SB203580 for $2 \mathrm{~h}$ before incubating with $50 \mu \mathrm{M}$ quercetin for $1080 \mathrm{~min}$ and then treated with $100 \mu \mathrm{g} / \mathrm{mL} \mathrm{CHX}$ for $1 \mathrm{~h}$.

\subsection{Fluorescence microscopy}

Fluorescence assay was performed as previously described [28]. Briefly, HepG2 cells were seeded (25.000 cells/well) on glass coverslips with DMEM F-12 supplemented with FBS for $24 \mathrm{~h}$ and changed to serum-free medium $24 \mathrm{~h}$ before the assay. After incubation with quercetin for the indicated times, cells were washed with PBS at room temperature and then fixed with $3.7 \%$ paraformaldehyde for $10 \mathrm{~min}$ at room temperature. Nuclei were visualized by using DAPI staining. The coverslips were mounted in Vectashield and images were taken with a Zeiss Axiovert 200M fluorescence microscope (Carl Zeiss Microimaging GmbH, Munich, Germany) at 63x magnification. AxioVisionRel 4.6 software was used for the analysis of the images obtained.

\subsection{Preparation of total cell lysates}

To detect p38 and phospho-p38, cells were lysed at $4^{\circ} \mathrm{C}$ in a buffer containing $25 \mathrm{mM}$ HEPES (pH 7.5), $0.3 \mathrm{M} \mathrm{NaCl}, 1.5 \mathrm{mM} \mathrm{MgCl}_{2}, 0.2 \mathrm{mM}$ EDTA, $0.5 \mathrm{mM}$ dithiothreitol (DTT), $0.1 \%$ Triton X100, $200 \mathrm{mM} \beta$-glycerolphosphate, $0.1 \mathrm{mM} \mathrm{Na}_{3} \mathrm{VO}_{4}, 2 \mu \mathrm{g} / \mathrm{mL}$ leupeptin and $1 \mathrm{mM}$ phenylmethylsulfonyl fluoride (PMSF). The supernatants were collected, assayed for protein concentration by using the Bio-Rad (Bio-Rad, Madrid, Spain) protein assay kit according to the manufacture's specifications, aliquoted and stored at $-80^{\circ} \mathrm{C}$ until used for Western blot analyses.

\subsection{Preparation of nuclear and cytosolic extracts}

To analyze Nrf2, cells were resuspended at $4^{\circ} \mathrm{C}$ in $10 \mathrm{mM}$ HEPES pH 7.9, $1.5 \mathrm{mM} \mathrm{MgCl} 2,10 \mathrm{mM}$ $\mathrm{KCl}, 0.5 \mathrm{mM}$ DTT, $0.2 \mathrm{mM}$ PMSF (buffer A), allowed to swell on ice for $10 \mathrm{~min}$, and then 
vortexed for 10s. Samples were centrifuged at $10,000 \mathrm{~g}$ for $2 \mathrm{~min}$ and the supernatant containing the cytosolic fraction was stored at $-80^{\circ} \mathrm{C}$. The pellet was resuspended in cold buffer B (20 mM HEPES pH 7.9, 25\% glycerol, $420 \mathrm{mM} \mathrm{NaCl}, 1.5 \mathrm{mM} \mathrm{MgCl} 2,0.2 \mathrm{mM}$ EDTA, $0.5 \mathrm{mM}$ DTT, $0.2 \mathrm{mM}$ PMSF, $2.5 \mu \mathrm{g} / \mathrm{mL}$ leupeptin, $2.5 \mu \mathrm{g} / \mathrm{mL}$ aprotinin) and incubated on ice for $20 \mathrm{~min}$ for high salt extraction. Cellular debris was removed by centrifugation at $13,000 \mathrm{~g}$ for $10 \mathrm{~min}$ at $4^{\circ} \mathrm{C}$, and the supernatant fraction containing nuclear protein extract was stored at $-80^{\circ} \mathrm{C}$. Proteins were measured using the Bradford reagent (Bio-Rad, Madrid, Spain) following the recommendations of the supplier.

\subsection{Western blot analysis}

Equal amounts of proteins $(100 \mu \mathrm{g})$ were separated by SDS-polyacrylamide gel electrophoresis and transferred to polyvinylidene difluoride (PVDF) filters (Protein Sequencing Membrane, Bio-Rad, Madrid, Spain). Membranes were probed with the corresponding primary antibody followed by incubation with peroxide-conjugated anti-rabbit immunoglobulin (GE Healthcare, Madrid, Spain) or peroxide-conjugated anti-mouse immunoglobulin only for p-p38 (Sigma, Madrid, Spain). Blots were developed with the ECL system (GE Healthcare, Madrid, Spain). Antigrowth factor receptorbound protein-2 (anti-GRB2) and anti-poly(ADPribose) polymerase (anti-PARP) antibodies were used as markers for the cytosolic and nuclear extracts, respectively. Normalization of Western blot was ensured by $\beta$-actin and bands were quantified using a scanner and accompanying software.

\subsection{Measurement of the Nrf2 DNA binding activity}

The DNA binding of Nrf2 was measured with a colorimetric non-radioactive Nrf2 Transcription Factor ELISA Assay (Active Motif, Rixensart, Belgium) according to the manufacturer's instructions. Briefly, nuclear extracts were incubated in the oligonucleotide-coated wells. Then, wells were washed and incubated with the antibody against Nrf2. Addition of the secondary 
antibody conjugated to horseradish peroxidase provided a colorimetric readout. The absorbance of each well was measured using a microplate reader at $450 \mathrm{~nm}$ (Bio-Tek, Winooski, VT, USA).

\subsection{Cell viability assay}

Cell viability was determined using the crystal violet assay [11]. HepG2 cells were seeded at low density $\left(10^{4}\right.$ cells per well) in 96 -well plates, grown for $20 \mathrm{~h}$ and incubated with crystal violet $(0.2 \%$ in ethanol) for $20 \mathrm{~min}$. Plates were rinsed with water, allowed to dry, and 1\% sodium dodecylsulfate (SDS) added. The absorbance of each well was measured using a microplate reader at $570 \mathrm{~nm}$ (BioTek, Winooski, VT, USA).

\subsection{RNA semiquantitation by reverse transcriptase-polymerase chain reaction}

Total RNA from cultured HepG2 cells was extracted by RNeasy kit (Qiagen, IZASA, Barcelona, Spain). One microgram of total RNA was used for reverse transcription polymerase chain reaction (RT-PCR) analysis. PCR was performed using the following couples of primers: 5'TCCGCTGCAAATACATCTCC-3' and 5'-TGTTTCCCGTTGCCATTGAT-3' $\left(\mathrm{Ta}=55^{\circ} \mathrm{C}\right)$ for glutathione S-transferase (GST); 5'-GGCACAGGTAAAACCAAATAGTAAC-3' and 5'CAAATTGTTTAGCAAATGCAGTCA-3' $\left(\mathrm{Ta}=55^{\circ} \mathrm{C}\right)$ for glutamylcysteine synthetase (GCS); $5^{\prime}-$ CAGTGGGACTCACGGAAGAT-3' and 5'-TTCACTGCAACAGCAAAACC-3' $\left(\mathrm{Ta}=52^{\circ} \mathrm{C}\right)$ for glutathione reductase (GR); 5'-CCTCAAGTACGTCCGACCTG-3' and 5'TAGGAGTTGCCAGACTGCTG-3' $\left(\mathrm{Ta}=58^{\circ} \mathrm{C}\right)$ for glutathione peroxidase (GPx). Glyceraldehyde3-phosphate dehydrogenase (GAPDH) was used as housekeeping gene. Samples were incubated in an automated heat block (PCR express system, Thermo Hybaid, Middlesex, UK). The PCR products were electrophoresed on a $1.5 \%$ agarose gel containing ethidium bromide. Densitometric analysis was performed using a scanner and accompanying software. Band intensity was normalized to values for GAPDH that was used as an internal control. 


\subsection{Determination of reduced glutathione (GSH)}

The content of GSH was quantified by the fluorometric assay of Hissin and Hilf [29]. The method takes advantage of the reaction of GSH with $o$-phtalaldehyde at $\mathrm{pH}$ 8.0. After the different treatments, cells $\left(4 \times 10^{6}\right)$ were detached and homogenized by ultrasound with $5 \%$ trichloroacetic acid containing $2 \mathrm{mM}$ EDTA. Following centrifugation of cells for $30 \mathrm{~min}$ at $1,000 \mathrm{~g}, 50 \mu \mathrm{L}$ of the clear supernatant was transferred to a 96-multiwell plate for the assay. Fluorescence was measured at an excitation wavelength of $340 \mathrm{~nm}$ and an emission wavelength of $460 \mathrm{~nm}$. The results of the samples were referred to those of a standard curve of GSH. The precise protocol has been described elsewhere $[5,6]$.

\subsection{Determination of GPx and GR activities}

Treated cells were collected in PBS and centrifuged at $300 \mathrm{~g}$ for $5 \mathrm{~min}$. Cell pellets were resuspended in $20 \mathrm{mM}$ Tris containing $5 \mathrm{mM}$ EDTA and $0.5 \mathrm{mM}$ mercaptoethanol, sonicated and centrifuged at 3,000 $\mathrm{g}$ for $15 \mathrm{~min}$. Enzymatic activities were measured in the supernatants. The determination of the GPx activity is based on the oxidation of GSH by GPx, using $30 \mathrm{mM}$ tertbutylhydroperoxide as a substrate, coupled to the disappearance of NADPH by GR [30]. A cuvette containing assay buffer plus $0.1 \mathrm{M} \mathrm{GSH}, 50 \mathrm{U} / \mathrm{mL}$ GR and $9.6 \mathrm{mM}$ NADPH was used to blank the spectrophotometer prior to addition of the sample and $30 \mathrm{mM}$ tert-butyl hydroperoxide.

Additionally, a sample with cells treated with $400 \mu \mathrm{M}$ tert-butylhydroperoxide for 3 hours was used as an internal positive control for GPx overactivity (data not shown) [5]. GR activity was determined by following the decrease in absorbance due to the oxidation of NADPH utilized in the reduction of oxidized GSH [31]. Each sample was blanked at the spectrophotometer in the presence of assay buffer plus $15 \mathrm{mM}$ EDTA and $65 \mathrm{mM}$ oxidated glutathione prior to addition of $9.6 \mathrm{mM}$ NADPH. As for GPx activity, a sample with cells treated with $400 \mu \mathrm{M}$ tert-butylhydroperoxide for 
3 hours was used as an internal positive control for GR overactivity (data not shown) [5]. Protein was measured by the Bradford reagent (Bio-Rad, Madrid, Spain).

\subsection{Determination of GST activity}

GST activity was determined using a commercial fluorimetric activity assay kit (Biovision Research Products, CA, USA). Treated cells were collected in PBS and centrifuged at low speed $(300 \mathrm{~g}$ ) for $5 \mathrm{~min}$. Cell pellets were resuspended in sample buffer, sonicated and centrifuged at 3,000 $\mathrm{g}$ for $15 \mathrm{~min}$ and enzyme activity was measured in the supernatants. The assay utilizes monochlorobimane (MCB) as an artificial substrate and glutathione to determine total GST activity. GST catalyses the MCB-glutathione reactions and the fluorescence levels are proportional to the amount of GST present in the reaction medium. A fluorescent microplate reader at an excitation wavelength of $380 \mathrm{~nm}$ and an emission wavelength of $460 \mathrm{~nm}$ was used (Bio-Tek, Winooski, VT, USA). The results of the samples were referred to those of a standard curve of GST activity, and the GST standard was provided by the commercial kit. Protein was measured by the Bradford reagent.

\subsection{Statistics}

Prior to statistical analysis, data were tested for homogeneity of variances by the test of Levene; for multiple comparisons, one-way ANOVA was followed by the Bonferroni test when variances were homogeneous or by the Tamhane test when variances were not homogeneous. $P<0.05$ was considered significant. A SPSS version 17.0 program was used. 


\section{Results}

\subsection{Dose-effect of quercetin on Nrf2 and p38}

To investigate whether quercetin treatment in HepG2 cells was able to regulate key proteins related to the cellular response to chemical/oxidative stress [23, 26], p38-MAPK and Nrf2 protein expressions were analyzed. HepG2 cells were treated with 5-50 $\mu \mathrm{M}$ quercetin for 4 and $18 \mathrm{~h}$, as short- and long-term treatments, in order to study the regulatory effect of the flavonoid on p38MAPK and the antioxidant defense system both in potential non-toxic and toxic conditions, respectively. Figures $1 \mathrm{~A}$ and $1 \mathrm{~B}$ illustrate that a $4 \mathrm{~h}$ treatment with 10-50 $\mu \mathrm{M}$ quercetin increased the phosphorylated levels of p38 in HepG2 cells. In addition, $18 \mathrm{~h}$ of incubation with $5-25 \mu \mathrm{M}$ flavonoid induced the phosphorylation of $\mathrm{p} 38$, whereas $50 \mu \mathrm{M}$ quercetin showed comparable levels of phosphorylated p38 to those of control cells. Likewise, there was no difference in the total levels of p38.

Similarly, it was investigated whether quercetin treatment was able to regulate the transcription factor Nrf2 in HepG2 cells. No phosphorylated Nrf2 (100 kDa) was detected in the cytosolic fraction of HepG2 cells, as previously shown [28]. A 4h-treatment with 10 and $25 \mu \mathrm{M}$ quercetin significantly increased the nuclear translocation of $\mathrm{Nrf} 2(57 \mathrm{kDa})$ and the nuclear content of phosphorylated Nrf2 (100 kDa), whereas $50 \mu \mathrm{M}$ quercetin decreased both the Nrf2 phosphorylated levels and the nuclear/cytosolic Nrf2 ratio (Figures $1 \mathrm{C}-1 \mathrm{E}$ ). On the other hand, a $18 \mathrm{~h}$ treatment with 5-10 $\mu \mathrm{M}$ quercetin increased the nuclear translocation of Nrf2 (57 kDa) and the nuclear content of phosphorylated Nrf2 $(100 \mathrm{kDa})$, and both parameters decreased in the presence of $50 \mu \mathrm{M}$ quercetin. The integrity of the cytosolic and nuclear fractions was confirmed by the analysis of the compartment-specific cytosolic GRB2 and nuclear PARP proteins. These results suggest that the duration of the treatment and the concentration of quercetin have a prominent effect on the modulation of p38 and Nrf2 in HepG2 cells. 
Given that $50 \mu \mathrm{M}$ quercetin was the concentration that provoked the strongest induction of $\mathrm{p} 38$ after $4 \mathrm{~h}$ of treatment returning the phosphorylated levels of p38 to control values after $18 \mathrm{~h}$ of incubation, and showed an inhibitory effect on $\mathrm{Nrf} 2$ at both incubation times, this was the concentration selected for studying the contribution of p38 to the modulation of Nrf2 by quercetin in HepG2 cells.

\subsection{Subcellular localization of quercetin}

By using the fluorogenic properties of quercetin, the cellular localization of the flavonoid was studied upon its internalization, HepG2 cells were treated for different times with $50 \mu \mathrm{M}$ quercetin. Cell incubation resulted in a yellow-green fluorescent signal that was detected in a fluorescence microscope upon excitation at 350-525 nm and emission at 475-625 nm (Figure 2). The fluorescent signal of quercetin was mainly located in the nucleus of HepG2 cells as early as after 10min of incubation (Figure 2). The signal was observed up to $240 \mathrm{~min}$ of treatment and only after the longest incubation time (1080 min) was not detected (Figure 2). These results indicated that quercetin exhibited specific fluorescence and showed mainly a nuclear localization in HepG2 cells.

\subsection{Quercetin activates p38 in a time-dependent manner}

The activation of p38-MAPKs has traditionally been associated with the stress response and some apoptotic processes, although p38-MAPKs have also been implicated as positive regulators in cell survival [26]. Since variations in the phosphorylated levels of p38 could occur in a time-dependent manner, it was important to study the effect induced by quercetin on this protein through the time in HepG2 cells. To this end, total and phosphorylated (active form) protein expressions of p38 were analyzed. Treatment of HepG2 cells with quercetin resulted in an enhanced phosphorylation of p38 at 10-240 min, returning to control levels at the longest time tested (18 h) (Figures 3A and 3B). Total p38 protein levels did not change during quercetin exposure. 


\subsection{Time-course effect on Nrf2 modulation induced by quercetin}

$\mathrm{Nrf} 2$ is involved in the response to chemical/oxidative stress [23]. To assess the implication of Nrf2 on quercetin effects, time-course studies on the nuclear and cytosolic levels of this transcription factor were performed. Quercetin concurrently increased nuclear translocation of Nrf2 (57 kDa) and nuclear content of phosphorylated Nrf2 $(100 \mathrm{kDa})$ at $60 \mathrm{~min}$ of treatment, followed by a decrease at $240 \mathrm{~min}$ of quercetin exposure (Figures 4A-4C). This effect remained up to $1080 \mathrm{~min}$ of incubation as can be deduced from the decline in the nuclear phosphorylated content and nuclear/cytosolic ratio of Nrf2 (Figures 4A-4C). Therefore, quercetin early and transiently activates Nrf2 translocation to later decrease its mobilization.

To further investigate the time-course effect of quercetin on the Nrf2 regulation, Nrf2 DNA-binding activity was studied. Quercetin induced a transient increase of Nrf2 binding activity (60 min), and later showed a reduced binding activity (240 and $1080 \mathrm{~min}$ ) (Figure 4D). The profile of the effect on Nrf2 binding activity was similar to that observed for the nuclear phosphorylated content and nuclear/cytosolic ratio of this transcription factor (Figure 4A-4C). Thus, as previously suggested quercetin activated Nrf2 and DNA binding early and transiently to later induce the inhibition of this transcription factor.

\subsection{Role of p38 in quercetin-induced effects on cell viability and Nrf2}

To elucidate the contribution of $\mathrm{p} 38$ to the modulation of Nrf2 by quercetin, the effects of SB203580 a specific inhibitor of p38 were evaluated. HepG2 cells were previously exposed to SB203580 and then treated with $50 \mu \mathrm{M}$ quercetin during 4 or $18 \mathrm{~h}$.

First, the potential cytotoxicity was studied in these experimental conditions. Treatment of HepG2 cells with SB203580 followed by addition of quercetin did not modify cell viability after $4 \mathrm{~h}$ of incubation (Table 1). The reduced percentage of viable cells was partly restored by the selective blockade of p38 with SB203580 inhibitor after $18 \mathrm{~h}$ of quercetin treatment (Table 1). 
In addition, in quercetin-treated cells the selective blockade of p38 completely restored to control levels the Nrf2 phosphorylated values and the ratio of nuclear versus cytosolic Nrf2 levels after $4 \mathrm{~h}$ of incubation (Figures 5A-5C), whereas at $18 \mathrm{~h}$ of treatment a partial recovery in both $\mathrm{Nrf} 2$ phosphorylated levels and nuclear/cytosolic Nrf2 ratio was observed (Figures 5E-5G). These results suggested that p38 is involved in the modulation of Nrf2 induced by quercetin, as the inhibition of p38 completely or partly reverted the flavonoid-induced effects on Nrf2 depending on the length of the exposure to quercetin. In addition, cell viability was restored in part after $18 \mathrm{~h}$ of incubation with quercetin by inhibiting p38-MAPK.

Nrf2 DNA-binding activity was also studied after the inhibition of p38 by using SB203580. Q+SB203580 treated cells recovered the Nrf2 binding activity to control values after $4 \mathrm{~h}$ of incubation (Figure 5D), as occurred with the Nrf2 phosphorylated values and nuclear/cytosolic ratio (Figures 5A-5C). In addition, the decreased Nrf2 DNA-binding activity in quercetin-treated cells after $18 \mathrm{~h}$ resulted in a slight recovery on the Nrf2 DNA-binding activity when incubating cells with quercetin and SB203580 (Figure 5H). Comparable effects were observed for the Nrf2 phosphorylated values and the nuclear/cytosolic ratio after treating cells with quercetin $(50 \mu \mathrm{M})$ and SB203580 for $18 \mathrm{~h}$ (Figures 5E-5G). These data indicated that quercetin effects on Nrf2 binding activity were totally or moderately restored, depending on the duration of the treatment when p38 is inhibited.

\section{6. p38 inhibition stabilize Nrf2}

To clarify whether p38 inhibition contributes to the stimulation of the transcription factor by stabilizing Nrf2 protein, cells were pretreated with SB203580 for $2 \mathrm{~h}$ before incubating with $50 \mu \mathrm{M}$ quercetin during $1080 \mathrm{~min}$ and then treated with the inhibitor of protein synthesis CHX for $1 \mathrm{~h}$. The quercetin-decreased nuclear/cytosol ratio of Nrf2 was partly restored by the inhibition of p38, whereas additional treatment with CHX evoked comparable levels to those of untreated cells 
(Figure 6). These results revealed that the inhibition of p38 pathway seems to contribute to stabilize Nrf2 protein levels.

\subsection{Quercetin modulates GSH levels and antioxidant/detoxificant enzymatic activities. Role of p38}

Studies on the antioxidant enzyme induction by oxidative stress stimuli have shown that Nrf2 also plays a main part and that PI3K and ERK-MAPK pathways seem to be involved in the transduction of signals initiating gene activation [23]. To further address whether a similar mechanism is responsible for the regulation of the GSH and the activities of antioxidant/detoxifying enzymes induced by quercetin, the effect of the p38 inhibitor was assayed.

GSH concentration was evaluated as an index of the intracellular non-enzymatic antioxidant defenses. After $4 \mathrm{~h}$ treatment, $50 \mu \mathrm{M}$ quercetin evoked an increase in the concentration of GSH, whereas pretreatment with the p38 inhibitor returned the quercetin-enhanced GSH values to similar levels to those of untreated cells (Figure 7A). Quercetin alone or in combination with SB203580 did not induce any change in the GSH levels after $18 \mathrm{~h}$ of incubation (Figure 7A).

As shown in Figure 6B, pretreatment with SB203580 returned the quercetin-induced activity of GPx after 4 or $18 \mathrm{~h}$ of incubation to control values. Similarly, quercetin-induced GR activity was suppressed by SB203580 pretreatment after 4 or $18 \mathrm{~h}$ of incubation (Figure $7 \mathrm{C}$ ). After $18 \mathrm{~h}$ of the flavonol exposure, GST activity was enhanced, but the activity of this detoxifying enzyme remained unchanged after $4 \mathrm{~h}$ of treatment with quercetin (Figure 7D). Moreover, the p38 inhibitor did not affect GST activity at both tested times when compared to quercetin-treated cells (Figure 7D). These results illustrated that the p38 pathway seems to be involved in the quercetin-induced activation of cellular antioxidant/detoxificant defenses. 


\subsection{Involvement of p38 in quercetin-regulated antioxidant/detoxificant enzymatic gene expressions}

The effect of $50 \mu \mathrm{M}$ quercetin on glutathione-related enzymes gene expression was further examined. The increased GPx mRNA expression induced by quercetin treatment $(4 \mathrm{~h})$ was reverted to control levels by the exposure to the p38 inhibitor (Figures $8 \mathrm{~A}$ and $8 \mathrm{~B}$ ). On the other hand, after 18h of treatment, quercetin did not modify the expression of GPx, and its mRNA levels remained also unchanged in cells incubated with the p38 inhibitor in comparison to untreated cells (Figures 8C and 8D). Pretreatment with SB203580 suppressed both the increased mRNA expression of GR and GCS at $4 \mathrm{~h}$ of incubation (Figures 8A and 8B). However, the expression levels of GCS and GR were unaltered in the presence of quercetin and/or the p38 inhibitor after $18 \mathrm{~h}$ of incubation, showing similar values to those of control cells (Figures 8C and 8D). Conversely, SB203580 significantly inhibited the quercetin-induced mRNA expression of GST (18 h), whereas cells treated for $4 \mathrm{~h}$ either with quercetin alone or in combination with the p38 inhibitor did not show any modification on GST gene expression when compared to control cells (Figures 8A and 8B). All these results suggested an involvement of p38 pathway in the quercetin-induced modulation of GSH-related antioxidant/detoxificant enzymes at $4 \mathrm{~h}$, although the defensive regulatory mechanisms seem to be attenuated through the time. 


\section{Discussion}

There has been a recent surge in interest in phytochemicals as medicinal anticancer agents due to their potential favorable efficacy [1]. Quercetin is consumed in the diet and a large body of evidence indicates that it has potent chemopreventive effects against a variety of malignant cell lines and in murine carcinoma models $[4,7,10]$.

Quercetin daily intake ranges between $5-40 \mathrm{mg} / \mathrm{day}$, but it has been estimated that its daily ingestion can reach 200-500 mg/day in people with a high intake of fruit and vegetables [32]. Published data on quercetin pharmacokinetics in humans suggest that a dietary supplement of 1-2 $\mathrm{g}$ of quercetin may result in plasma concentrations ranging between 10-50 $\mu \mathrm{M}$ [33]. In addition, it has been reported that after administration of quercetin in high doses, its metabolism mainly takes place in the liver instead of the small intestine [3]. In plasma, the main quercetin metabolites found are sulphated and glucuronidated derivatives, as well as $O$-methylquercetin and 3'-O-methylquercetin-3-Oglucuronide [32]. In addition, quercetin degradation by the microflora produces different phenolic acids, which are mainly 3,4-dihydroxyphenylacetic, 3-methoxy-4-hydroxyphenylacetic (homovanillic acid), and 3-hydroxyphenylacetic acid [32]. However, at present the potential contribution of quercetin metabolites to the biological activity is unclear and it should not be underestimated; its evaluation will require further studies.

In the present study, it is demonstrated that quercetin differently modulates p38 and Nrf2 depending on the concentration used and the length of the treatment. Thus, $50 \mu \mathrm{M}$ quercetin regulates GSHrelated antioxidant/detoxifying enzymes and Nrf2 by targeting p38-MAPK. Quercetin rapidly activates Nrf2 by up-regulating the phosphorylation and translocation of Nrf2 to later inhibit both effects and in parallel also transiently induces p38-MAPK activation. These actions caused by quercetin seem to play an important role both in the regulation of important glutathione-related enzymes and in the final induction of cell death. 
The intracellular biotransformation of quercetin by HepG2 cells was evidenced by the gradual disappearance of its intrinsic fluorescence. However, it should be considered that quercetin and/or its metabolites could contribute to the observed fluorescence. This signal of fluorescence was mainly located in the nucleus after a short incubation time, in agreement with Nifli et al. [34], suggesting that quercetin internalization is coupled to its transient binding to specific target proteins.

Activation of $\mathrm{p} 38$-MAPK has been positively related to cell survival and more traditionally to the stress response and apoptosis, and its role in the programmed cell death depends on the cell type and the stimuli [26]. Consequently, p38-MAPK may act as a mediator of apoptosis in fibroblasts [35], cardiomyocytes [35] and in hepatic cells [36]. Thus, quercetin-induced activation of p38 could be associated to the up-regulation of proapoptotic proteins and down-regulation of survival pathways, which would lead to cell death, in agreement with the present and previous studies [10$12,35]$.

Nrf2 seems to have an important role in the protection against induced liver injury [23, 37]. Thus, Nrf2 regulates the response to cellular stress and cell survival/proliferation [8, 37-39]. In line with this, it has been demonstrated that polyphenols alone, as well as a few glycosylated such as quercitrin, could activate $\operatorname{Nrf} 2[8,16,17,24,28]$, which is in agreement with the present study. Nrf2 phosphorylation has been described as a critical event for the nuclear translocation of this transcription factor and its transcriptional activity [23, 25, 28]. Moreover, Nrf2 DNA-binding activity could be linked to the nuclear phosphorylated Nrf2 levels (100 kDa) described in the present study.

Nrf2 may also define the initial threshold for toxicity by controlling, at least in part, constitutive aspects of cell defense $[24,37,38]$. In this regard, it has been described that an agent could stimulate the nuclear accumulation of $\mathrm{Nrf} 2$ at non-cytotoxic concentrations or after a short time of incubation, although it could induce significant cytotoxicity at longer times of exposure [37]. 
Therefore, the Nrf2-ARE pathway could act as a sensor and respond to chemical stress before the onset of the cytotoxicity. In line with this, it could be suggested that Nrf2 is activated in response to mild and acute quercetin treatment as an adaptive response to guard against oxidative and inflammatory cell damage, but Nrf2 might not play a protective role against long and cytotoxic flavonoid exposure.

Post-translational modification of Nrf2 by various protein kinase signaling pathways can affect its nuclear translocation. ERK, JNK, PI3K and PKC are some of the kinases identified as responsible for Nrf2 phosphorylation [23]. However, the effect of p38 on Nrf2 seems to be controversial, as it has been reported that Nrf2 activation could be attenuated by the overexpression of p38-MAPKs $[39,40]$. On the contrary, it has also been described that p38 activation leads to ARE induction [41, 42]. A possible explanation for these different findings is that while certain ARE inducers may activate p38-MAPK, others may inhibit p38-MAPK [43]. In line with this, quercetin has been reported to upregulate Nrf2 through the activation of both its transcription and post-transcription modifications [16]. In the present study, it seems that Nrf2 is regulated by posttranslational alterations since the use of p38-MAPK pathway inhibitor increases the stability of Nrf2, as previously shown [43].

The capacity of cells to maintain homeostasis during oxidative stress resides in the induction of protective enzymes, as well as non-enzymatic defenses such as GSH [5, 7, 8, 18-20, 22, 44], playing Nrf2 an important role in the regulation of these processes [8, 16, 21, 24]. Consequently, the enhancement of GSH concentration and glutathione-related enzymes seem to prepare cells to prevent a potential oxidative insult and suppress oxidative-stress induced damage $[5,6,19,21,22,45]$. Consistent with this, our results revealed that 4 and $18 \mathrm{~h}$ treatment of HepG2 cells with quercetin increased the activity of GPx and GR, as well as GSH content after $4 \mathrm{~h}$ of incubation. In this regard, an increase in GSH concentration induced by quercetin has been previously found in HepG2 cells and in the liver [6, 17, 46]. Furthermore, the enhancement in GPx 
and GR enzyme activities after $4 \mathrm{~h}$ of treatment was correlated with a parallel augment in their mRNA levels, as well as GCS expression, suggesting that quercetin can modulate GSH-related enzymes gene expression as previously described for quercetin and other phenolic compounds [18, 46]. Interestingly, the enhanced activities of GPx and GR were not accompanied by increased mRNA levels after $18 \mathrm{~h}$ of quercetin exposure, and similar values to untreated cells were observed in these conditions. This feature could be related to the fact that the Nrf2 activation occurs as an early event; in addition, the elevated GPx activity has been observed after submitting HepG2 cells to oxidative challenges $[19,44]$, and an augmented GR activity has been related to an enhancement in the metabolism of the xenobiotic and flavonoids [14, 44]. Similarly, after an acute stress GSH levels could be temporally decreased and later recovered due to an increase in GCS activity and mRNA [46]; this has been considered as an indication of a cellular self-protection against a sublethal toxic insult [14]. All these results suggest that the final cytotoxicity associated to quercetin treatment and the unchanged levels of mRNA expression for GPx, GR and GCS (18 h) might imply impairment in the machinery involved in gene transcription and mRNA synthesis of the antioxidant enzymes. In fact, cell death caused by quercetin may indicate that the toxic insult has overwhelmed the defense mechanisms, such as Nrf2 response, as previously shown for other agents [38]. In line with this, it has been reported the activation of Nrf2 and related genes to this transcription factor in cells undergoing apoptosis, suggesting that the treatment with dietary polyphenolic might not be enough to protect against cell death [24].

The detoxification enzyme GST catalyses the reaction of endogenous GSH with numerous electrophiles to yield less toxic conjugates and facilitate their elimination [18]. GST activity and mRNA expression increased after $18 \mathrm{~h}$ of treatment with quercetin. Different natural compounds, and also quercetin and its glycosylated form, induce GST activity as a mechanism of protection against oxidative stress $[8,18,19,45,47]$. On the other hand, a number of studies have shown a correlation between overexpression of GST and the development of resistance towards various 
anticancer drugs [48]. Thereby, induction of GST may not be favorable for cancer chemotherapy and a significant inverse correlation has been demonstrated between GST enzyme activity and tumor incidence $[45,49]$. In this line, it has been recently reported that epigallocatechin-3-gallate and sulforaphane augment Nrf2 and detoxifying enzyme levels, which has been associated with a chemoresistance to cytotoxic drugs [50]. However, other authors suggest that the effect of polyphenols on GST activity may depend on the amount of phenolic compound incorporated into the cells [47]. In any case, it should be highlighted that many researches have shown that quercetin possesses anticancer effects on different models through different mechanisms $[1,10,14]$. Taken all these results together, it could be proposed that the increased endogenous defense capacity evoked by quercetin could be a critical determinant in cell protection/resistance against the induced injury. The apparent correlation between p38 and Nrf2-mediated antioxidant/detoxifying enzyme suggests that Nrf2 could be a downstream target of this MAPK after quercetin treatment. In this line, pretreatment with the p38-MAPK inhibitor prior to exposure to quercetin activated Nrf2 [40], which suggests that p38-MAPK signaling pathway may be implicated in the nuclear localization and stability of Nrf2 protein during quercetin-induced gene expression. Thus, this study demonstrates that p38 pathway is involved in the cell defense through the modulation of Nrf2 and antioxidant/detoxificant enzymes after quercetin exposure.

In summary, the present study demonstrates that a possible mechanism of action of quercetin may be by regulating the GSH-related antioxidant/detoxifying enzymes. Thus, p38 is implicated in the modulation of Nrf2 and GSH-related enzymes in quercetin-treated cells at a shorter time than that causing cell damage. However, this response is impaired at longer times of incubation, when the toxic insult has overwhelmed the cellular defense mechanisms. These results might have implications for humans in terms of use of flavonoids in an attempt to support cancer chemotherapy. Consequently, further efforts are needed to elucidate the benefits and risks of flavonoids since they are used increasingly in dietary supplements. 


\section{Conflict of interests}

The authors declare that there are no conflicts of interest.

\section{Acknowledgements}

This work was supported by the grants $200870 I 198$ (CSIC), and AGL2004-302, AGL2007-64042 and CSD2007-00063 from the Spanish Ministry of Science and Innovation (CICYT). A.B.

Granado-Serrano was a predoctoral fellow of the Spanish Ministry of Science and Education. 


\section{References}

[1] S. Ramos, Effects of dietary flavonoids on apoptotic pathways related to cancer chemoprevention, J Nutr Biochem 18 (2007) 427-442.

[2] J. Spencer, G. Chowrimootoo, R. Choudhury, E. Debnam, S. Srai, C. Rice-Evans, The small intestine can both absorb and glucuronidate luminal flavonoids, FEBS Lett 4582 (1999) 224-230.

[3] H. Tapiero, K.D. Tew, G.N. Ba, G. Mathe, Polyphenols: do they play a role in the prevention of human pathologies?, Biomed Pharmacother 56 (2002) 200-207.

[4] C. Chi, Y. Chang, Y. Ou, C. Hsieh, Y. Lui, F. Peng, T. Liu, Effect of quercetin on the in vitro and in vivo growth of mouse hepatoma cells, Oncol Res 4 (1997) 1021-1024.

[5] M. Alia, S. Ramos, R. Mateos, A. Granado-Serrano, L. Bravo, L. Goya, Quercetin protects human hepatoma cell line (HepG2) against oxidative stress induced by tertbutyl hydroperoxide, Toxicol Appl Pharmacol 212 (2006) 110-118.

[6] M. Alia, R. Mateos, S. Ramos, E. Lecumberri, L. Bravo, L. Goya, Influence of quercetin and rutin on growth and antioxidant defense system of a human hepatoma cell line (HepG2), Eur J Nutr 451 (2006) 19-28.

[7] Y.-F. Chang, Y.-C. Hsu, H.-F. Hung, H.-J. Lee, W.-Y. Lui, C.-W. Chi, J.-J. Wang, Quercetin induces oxidative stress and potentiates the apoptotic action of 2-methoxyestradiol in human hepatoma cells, Nutr Cancer 61 (2009) 735-774.

[8] M. Ding, J. Zhao, L. Bowman, Y. Lu, X. Shi, Inhibition of AP-1 and MAPK signaling and activation of Nrf2/ARE pathway by quercitrin, Int J Oncol 36 (2010) 59-67.

[9] S. Chowdhury, K. Kishino, R. Satoh, K. Hashimoto, H. Kikuchi, H. Nishikawa, Y. Shirataka, H. Sakagami, Tumor-specificity and apoptosis-inducing activity of stilbenes and flavonoids, Anticancer Res 253B (2005) 2055-2063. 
[10] A. Granado-Serrano, M. Martín, L. Bravo, L. Goya, S. Ramos, Quercetin induces apoptosis via caspase activation, regulation of Bcl-2, and inhibition of PI-3-Kinase/Akt and ERK pathways in a human hepatoma cell line (HepG2), J Nutr 136 (2006) 2715-2721.

[11] A. Granado-Serrano, M. Martin, L. Bravo, L. Goya, S. Ramos, Time-course regulation of quercetin on cell survival/proliferation pathways in human hepatoma cells, Mol Nutr Food Res 52 (2008) 457-464.

[12] A. Granado-Serrano, M. Martín, L. Bravo, L. Goya, S. Ramos, Quercetin modulates NF- $\kappa \mathrm{B}$ and AP-1/JNK pathways to induce cell death in human hepatoma cells, Nutr Cancer 62 (2010) 390-401.

[13] J.-H. Yang, T. Hsia, H.-M. Kuo, P.-D. Lee Chao, C.-C. Chou, Y.-H. Wei, J.-G. Chung, Inhibition of lung cancer cell growth by quercetin glucuronides via G2/M arrest and induction of apoptosis, Drug Metab Disposition 34 (2006) 296-304.

[14] E. Rodgers, M. Grant, The effect of the flavonoids, quercetin, myricetin and epicatechin on the growth and enzyme activities of MCF7 human breast cancer cells, Chem Biol Interact 116 (1998) 213-228.

[15] G. Galati, P.J. O'Brien, Potential toxicity of flavonoids and other dietary phenolics: significance for their chemopreventive and anticancer properties, Free Rad Biol Med 37 (2004) 287-303.

[16] S. Tanigawa, M. Fujii, D.-X. Hou, Action of Nrf2 and Keap1 in ARE-mediated NQO1 expression by quercetin, Free Rad Biol Med 42 (2007) 1690-1703.

[17] P. Yao, A. Nussler, L. Liu, L. Hao, F. Song, A. Schirmeier, N. Nussler, Quercetin protects human hepatocytes from ethanol-derived oxidative stress by inducing heme oxygenase-1 via the MAPK/Nrf2 pathways, J Hepatol 47 (2007) 253-261. 
natural antioxidant compounds in biological systems: involvement of glutathione-related enzymes, J Nutr Biochem 16 (2005) 577-586.

[19] J. Garcia-Alonso, G. Ros, M.J. Periago, Antiproliferative and cytoprotective activities of a phenolic-rich juice in HepG2 cells, Food Res Int 39 (2006) 982-991.

[20] G. Valdameri, M. Trombetta-Lima, P.R. Worfel, A.R.A. Pires, G.R. Martinez, G.R. Noleto, S.M.S.C. Cadena, M.C. Sogayar, S.M.B. Winnischofer, M.E.M. Rocha, Involvement of catalase in the apoptotic mechanism induced by apigenin in HepG2 human heptoma cells, Chem Biol Interact 193 (2011) 180-189.

[21] X. Wang, X.-I. Ye, R. Liu, H.-L. Chen, H. Bai, X. Liang, X.-D. Zhang, Z. Wang, W.-I. Li, C.-X. Hai, Antioxidant activities of oleanolic acid in vitro: Possible role of Nrf2 and MAP kinases, Chem Biol Interact 184 (2010) 328-337.

[22] C.F. Lima, P.C. Valentao, P.B. Andrade, R.M. Seabra, M. Fernandes-Ferreira, C. Pereira-Wilson, Phenolic compounds protect HepG2 cells from oxidative damage: relevance of glutathione levels, Chem Biol Interact 167 (2007) 107-115.

[23] A.L. Eggler, K.A. Gay, A.D. Mesecar, Molecular mechanisms of natural products in chemoprevention: Induction of cytoprotective enzymes by Nrf2, Mol Nutr Food Res 52 (2008) S84-S94.

[24] C.K. Andreadi, L.M. Howells, P.A. Atherfold, M.M. Manson, Involvement of Nrf2, p38, B-Raf, and nuclear factor-kB, but not phosphatidylinositol 3-kinase, in induction of hemeoxygenase-1 by dietary polyphenols, Mol Pharmacol 69 (2006) 1033-1040.

[25] J. Pi, Y. Bai, J.M. Reece, J. Williams, D. Liu, M.L. Freeman, W.E. Fahl, D. Shugar, J. Liu, W. Qu, S. Collins, M.P. Waalkes, Molecular mechanism of human Nrf2 activation and degradation: Role of sequential phosphorylation by protein kinase CK2, Free Rad Biol Med 42 (2007) 1797-1806. 
[26] A.R. Nebreda, A. Porras, p38 MAP kinases: beyond the stress response, TIBS 25 (2000) 257-260.

[27] E. Balogun, M. Hoque, P. Gong, E. Killeen, C. Green, J. Foresti, R. Motterlini, Curcumin activates the haem oxygenase- 1 gene via regulation of Nrf2 and the antioxidant response element, Biochem J 371 (2003) 887-895.

[28] A.B. Granado-Serrano, M.A. Martin, G. Haegeman, L. Goya, L. Bravo, S. Ramos, Epicatechin induces NF-kB, activator protein-1 (AP-1) and nuclear transcription factor erythroid 2p45-related factor-2 (Nrf2) via phosphatidylinositol-3-kinase/protein kinase B (PI3K/AKT) and extracellular regulated kinase (ERK) signalling in HepG2 cells, Brit J Nutr 103 (2010) 168-179. [29] P. Hissin, R. Hilf, A fluorometric method for determination of oxidised and reduced glutathione in tissues, Anal Biochem 74 (1976) 214-226.

[30] W. Gunzler, H. Kremers, L. Flohe, An improved coupled test procedure for glutathione peroxidase in blood, Z Klin Chem Klin Biochem 12 (1974) 444-448.

[31] D. Goldberg, R. Spooner, Glutathione reductase, In: Bergmeyer, H.V. (Ed.). Methods of enzymatic analysis, Weinheim, Verlag-Chemie. (1987) 258-265.

[32] C. Manach, A. Scalbert, C. Morand, C. Remesy, L. Jimenez, Polyphenols: food sources and bioavailability, Am J Clin Nutr 79 (2004) 727-747.

[33] W. Wätjen, G. Michels, B. Steffan, P. Niering, Y. Chovolou, A. Kampkötter, Q.-H. Tran-Thi, P. Proksch, R. Kahl, Low concentrations of flavonoids are protective in rat H4IIE cells whereas high concentrations cause DNA damage and apoptosis, J Nutr 135 (2005) 525-531. [34] A.-P. Nifli, P.A. Theodoropoulos, S. Munier, C. Castagnino, E. Roussakis, H.E. Katerinopoulos, J. Vercauteren, E. Castanas, Quercetin exhibits a specific fluorescence in cellular milieu: a valuable tool for the study of its intracellular distribution, J Agric Food Chem 55 (2007) 2873-2878. 
Benito, A.R. Nebreda, p38-alpha mitogen-activated protein kinase sensitizes cells to apoptosis induced by different stimuli, Mol Biol Cell 15 (2004) 922-933. W.Y.W. Lee, K.W.K. Liu, J.H.K. Yeung, Reactive oxygen species-mediated kinase activation by dihydrotanshinone in tanshinones-induced apoptosis in HepG2 cells, Cancer Lett 285 (2009) 46-57.

[37] I.M. Copple, C.E. Goldring, R.E. Jenkins, A.J.L. Chia, L.E. Randle, J.D. Hayes, N.R. Kitteringham, B.K. Park, The hepatotoxic metabolite of acetaminophen directly activates the Keap1-Nrf2 cell defense system, Hepatology 48 (2008) 1292-1301.

[38] C.E.P. Goldring, N.R. Kitteringham, R. Elsby, L.E. Randle, Y.N. Clement, D.P. Williams, M. McMahon, J.D. Hayes, K. Itoh, M. Yamamoto, B.K. Park, Activation of hepatic Nrf2 in vivo by acetaminophen in CD-1 mice, Hepatology 39 (2004) 1267-1276.

[39] S. Naidu, V. Vijayan, S. Santoso, T. Kietzmann, S. Immenschuh, Inhibition and genetic deficiency of p38 MAPK up-regulates heme oxygenase-1 gene expression via Nrf2, J. Immunol. 182 (2009) 7048-7057.

[40] Y.-S. Keum, S. Yu, P.P. Chang, X. Yuan, J.-H. Kim, C. Xu, J. Han, A. Agarwal, A.N. Tony Kong, Mechanism of action of sulforaphane: inhibition of p38 mitogen-activated protein kinase isoforms contributing to the induction of antioxidant response element-mediated heme oxygenase-1 in human hepatoma HepG2 cells, Cancer Res 66 (2006) 8804-8813.

[41] J. Alam, C. Wicks, D. Stewart, P. Gong, C. Touchard, S. Otterbeini, A.M.K. Choii, M.E. Burow, J.S. Tou, Mechanism of heme oxygenase-1 gene activation by cadmium in MCF-7 mammary epithelial cells. Role of p38 kinase and Nrf2 transcription factor, J. Biol. Chem 275 (2000) $27694-27702$.

[42] K.W. Kang, J.H. Ryu, S.G. Kim, The essential role of phosphatidylinositol 3-kinase and of p38 mitogen-activated protein kinase activation in the antioxidant response element 
mediated rGSTA2 induction by decreased glutathione in H4IIE hepatoma cells, Mol Pharmacol 58 (2000) 1017-1025.

[43] C.T. Yeh, G.C. Yen, Involvement of p38 MAPK and Nrf2 in phenolic acid-induced Pform phenol sulfotransferase expression in human hepatoma HepG2 cells, Carcinogenesis 27 (2006) 1008-1017.

[44] M. Alia, S. Ramos, R. Mateos, L. Bravo, L. Goya, Response of the antioxidant defense system to tert-butyl hydroperoxide and hydrogen peroxide in a human hepatoma cell line (HepG2), J Biochem Mol Toxicol 192 (2005) 119-128.

[45] S. De, J. Chakraborty, R.N. Chakraborty, S. Das, Chemopreventive activity of quercetin during carcinogenesis in cervix uteri in mice, Phytother Res 14 (2000) 347-351.

[46] G. Scharf, S. Prustomersky, S. Knasmuller, R. Schulte-Hermann, W.W. Huber, Enhancement of glutathione and g-glutamylcysteine synthetase, the rate limiting enzyme of glutathione synthesis, by chemoprotective plant-derived food and beverage components in the human hepatoma cell line HepG2, Nutr Cancer 45 (2003) 74-83.

[47] T. Nishinaka, Y. Ichijo, M. Ito, M. Kimura, M. Katsuyama, K. Iwata, T. Miura, T. Terada, C. Yabe-Nishimura, Curcumin activates human glutathione S-transferase P1 expression through antioxidant response element, Toxicol Letters 170 (2007) 238-247.

[48] D.M. Townsend, K.D. Tew, The role of glutathione-S transferase in anti-cancer drug resistance, Oncogene 22 (2003) 7369-7375.

[49] W.H. Peters, H.M. Roelfos, M.P. Hectors, F.M. Nagengast, J.B. Jansen, Glutathione and glutathione S-transferases in Barrett's epithelium, Brit J Cancer 67 (1993) 1413-1417.

[50] L. Hu, W. Miao, M. Loignon, M. Kandouz, G. Batist, Putative chemopreventive molecules can increase Nrf2-regulated cell defense in some human cancer cell lines, resulting in resistance to common cytotoxic therapies, Cancer Chemother Pharmacol 66 (2010) 467-474. 


\section{Legends to figures}

Figure 1. Dose-dependent effects of quercetin on p38 and Nrf2 after 4 and 18 h of treatment. Effects on the basal levels of phosphorylated p38 (Thr180/Tyr182) and total p38 after incubating HepG2 cells for 4 (white bars) or 18 h (black bars). (A) Representative blots. (B) Percentage data of the p-p38/p38 ratio relative to controls (means $\pm S D, n=5$ ). Normalization of Western blots was ensured by $\beta$-actin. Effects of quercetin on cytosolic and nuclear Nrf2 levels (100 and $57 \mathrm{kDa}$ ) after for 4 (white bars) or $18 \mathrm{~h}$ (black bars) treatment. (C) Bands of representative experiments. AntiGRB2 and anti-PARP antibodies were used as markers for the cytosolic and nuclear extracts, respectively. (D) Percentage values of nuclear levels of phosphorylated Nrf2 (100 kDa) relative to the control condition (means $\pm \mathrm{SD}, \mathrm{n}=6)(\mathrm{E})$ Nuclear/cytosolic Nrf2 (57 kDa) ratio of bands densitometric quantification (means $\pm \mathrm{SD}, \mathrm{n}=6$ ). Normalization of Western blots was ensured by $\beta$ actin and it was not included in the plot due to the complexity of the figure. Means without a common letter differ, $P<0.05$.

Figure 2. Fluorescence images of the subcellular localization of quercetin. To visualize nuclei, 6diamidino-2-phenylindole (DAPI) staining was used. These results are representative of two independent experiments.

Figure 3. Time-dependent effects of quercetin on the basal levels of phosphorylated p38 (Thr180/Tyr182) and total p38. (A) Representative blots. (B) Percentage data of the p-p38/p38 ratio relative to controls (means $\pm \mathrm{SD}, \mathrm{n}=7$ ). Normalization of Western blots was ensured by $\beta$-actin. Means without a common letter differ, $P<0.05$. 
Figure 4. Time-course effects of quercetin on cytosolic and nuclear Nrf2 levels (100 and $57 \mathrm{kDa})$, and on DNA binding activity. (A) Bands of representative experiments. Anti-GRB2 and anti-PARP antibodies were used as markers for the cytosolic and nuclear extracts, respectively. (B) Percentage values of nuclear levels of phosphorylated Nrf2 $(100 \mathrm{kDa})$ relative to the control condition (means $\pm \mathrm{SD}, \mathrm{n}=7)(\mathrm{C})$ Nuclear/cytosolic Nrf2 (57 kDa) ratio of bands densitometric quantification (means $\pm \mathrm{SD}, \mathrm{n}=8$ ). Normalization of Western blots was ensured by $\beta$-actin and it was not included in the plot due to the complexity of the figure. (D) DNA-binding activity of Nrf2 (means $\pm S D, n=8$ ). Absorbance was measured at $450 \mathrm{~nm}$. Means without a common letter differ, $P<0.05$.

Figure 5. Effects of quercetin and SB203580 (SB) plus quercetin treatments on cytosolic and nuclear Nrf2 levels (100 and $57 \mathrm{kDa}$ ), and on DNA binding activity at 4 and $18 \mathrm{~h}$. HepG2 cells were incubated with $50 \mu \mathrm{M}$ quercetin for $4 \mathrm{~h}$ or $18 \mathrm{~h}$ in the presence or absence of $10 \mu \mathrm{M} \mathrm{SB}$. (A) Bands of representative experiments after $4 \mathrm{~h}$ treatment. (B) Percentage of $100 \mathrm{kDa}$ nuclear Nrf2 relative to control condition, (C) $57 \mathrm{kDa}$ nuclear/cytosolic Nrf2 ratio (means $\pm \mathrm{SD}, \mathrm{n}=5$ ). (D) DNAbinding activity of Nrf2 after $4 \mathrm{~h}$ of exposure (means $\pm S D, n=8$ ). (E) Representative blot after $18 \mathrm{~h}$ of exposure. (F) Values of $100 \mathrm{kDa}$ nuclear Nrf2 are shown as a percent relative to the control condition and (G) $57 \mathrm{kDa}$ nuclear/cytosolic Nrf2 ratio (means $\pm \mathrm{SD}, \mathrm{n}=6$ ). Anti-GRB2 and antiPARP antibodies were used as markers for the cytosolic and nuclear extracts, respectively. Normalization of Western blots was ensured by $\beta$-actin and it was not included in the plot due to the complexity of the figure. (H) DNA-binding activity of Nrf2 after $18 \mathrm{~h}$ of incubation (means \pm $\mathrm{SD}, \mathrm{n}=8$ ). Absorbance was measured at $450 \mathrm{~nm}$. Different letters on bars denote statistically significant differences, $P<0.05$.

Figure 6. Effects of quercetin, SB203580 (SB) and cycloheximide (CHX) on cytosolic and nuclear Nrf2 levels $(57 \mathrm{kDa})$ at $18 \mathrm{~h}$. HepG2 cells were incubated with $50 \mu \mathrm{M}$ quercetin for $18 \mathrm{~h}$ in the 
presence or absence of $10 \mu \mathrm{M} \mathrm{SB}$ and/or $100 \mu \mathrm{g} / \mathrm{mL}$ CHX. (A) Representative blots. Anti-GRB2 and anti-PARP antibodies, used as markers for the cytosolic and nuclear extracts, respectively. (B) Nrf2 nuclear/cytosolic ratio (57 kDa, means $\pm \mathrm{SD}, \mathrm{n}=6$ ). Normalization of Western blots was ensured by $\beta$-actin, yet it was not included in the plot due to the complexity of the figure. Means without a common letter differ, $P<0.05$.

Figure 7. Effects of quercetin and SB203580 (SB) plus quercetin treatments on (A) GSH levels, (B) GPx, (C) GR and (D) GST activities. HepG2 cells were incubated with $50 \mu \mathrm{M}$ quercetin for 4 (white bars) or $18 \mathrm{~h}$ (black bars) in the presence or absence of $10 \mu \mathrm{M} \mathrm{SB}$. Values are means of eight to twelve different samples per condition. Different letters on bars denote statistically significant differences, $P<0.05$

Figure 8. Effects of quercetin and SB203580 (SB) plus quercetin treatments on GPx, GR, GCS and GST mRNA levels after (A) $4 \mathrm{~h}$ or (C) $18 \mathrm{~h}$ quercetin $(50 \mu \mathrm{M})$ exposure. Representative RT-PCR of three different experiments. Percentages of mRNA levels of GPx, GR, GCS and GST after (B) 4 $\mathrm{h}$ or (D) $18 \mathrm{~h}$ (means $\pm \mathrm{SD}$ ). Means without a common letter differ, $P<0.05$. 
Table 1. Effect of quercetin on cell viability. HepG2 cells were treated with $50 \mu \mathrm{M}$ quercetin for 4 and 18 hours, respectively and cell viability was determined as relative percent of crystal violet stained control cells. Data represent means \pm SD of 8-10 separate experiments. Means in a column without a common letter differ, $P<0.05$.

Quercetin

Time (hours)

$(50 \mu M)$

$4 \mathrm{~h}(\%$ of viable cells $) \quad 18 \mathrm{~h}(\%$ of viable cells $)$

$\begin{array}{lcc}\text { C } & 100.0 \pm 13.5^{\mathrm{a}} & 100.0 \pm 15.1^{\mathrm{a}} \\ \mathrm{Q} & 82.9 \pm 11.3^{\mathrm{a}} & 59.1 \pm 5.25^{\mathrm{b}} \\ \mathrm{Q}+\mathrm{SB} & 81.6 \pm 10.3^{\mathrm{a}} & 77.8 \pm 8.4^{\mathrm{c}}\end{array}$




\section{Figure 1.}

\section{C}

Nrf2 (cyt, 57 kDa)

A

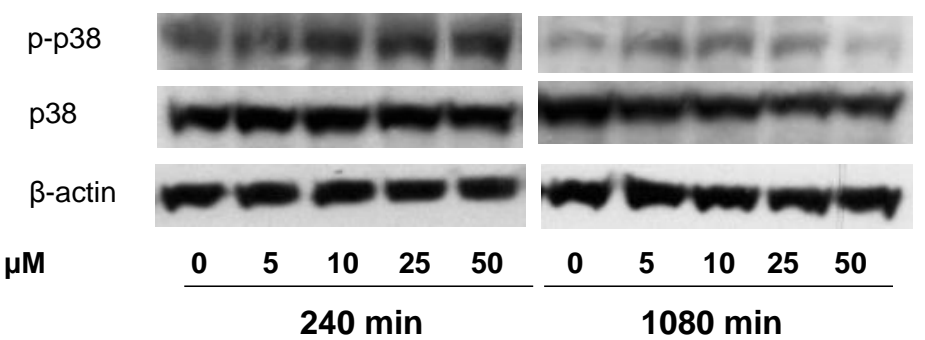

B

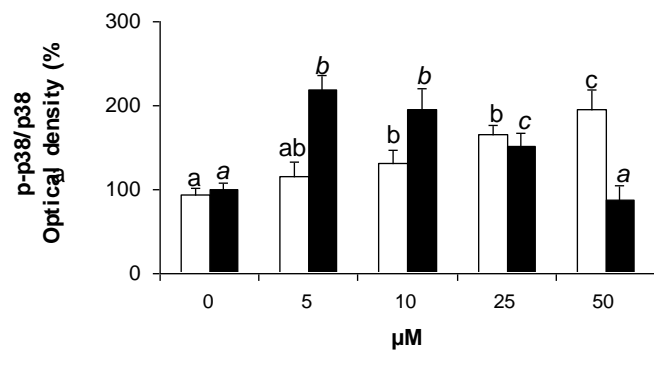

GRB2

Nrf2 (nuc, 100 kDa)

Nrf2 (nuc, 57 kDa)

PARP

$\mu \mathrm{M}$

\section{F}

$-\infty=$

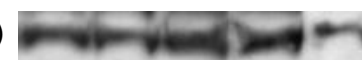

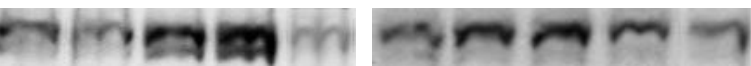

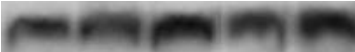

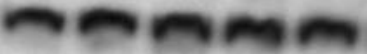

D

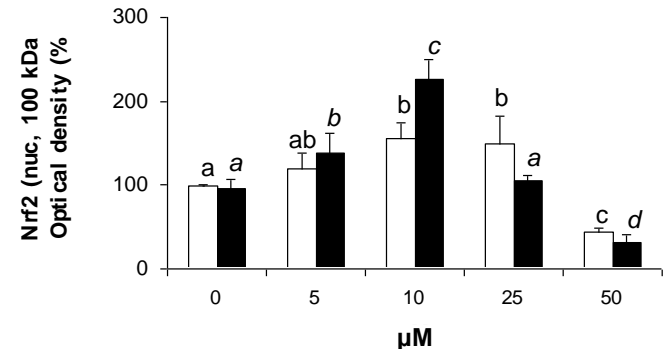

E

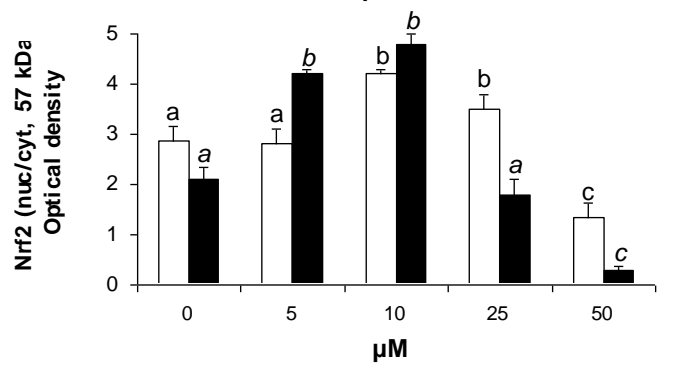

$\square \quad 240 \mathrm{~min}$

- $1080 \mathrm{~min}$ 
Figure 2.

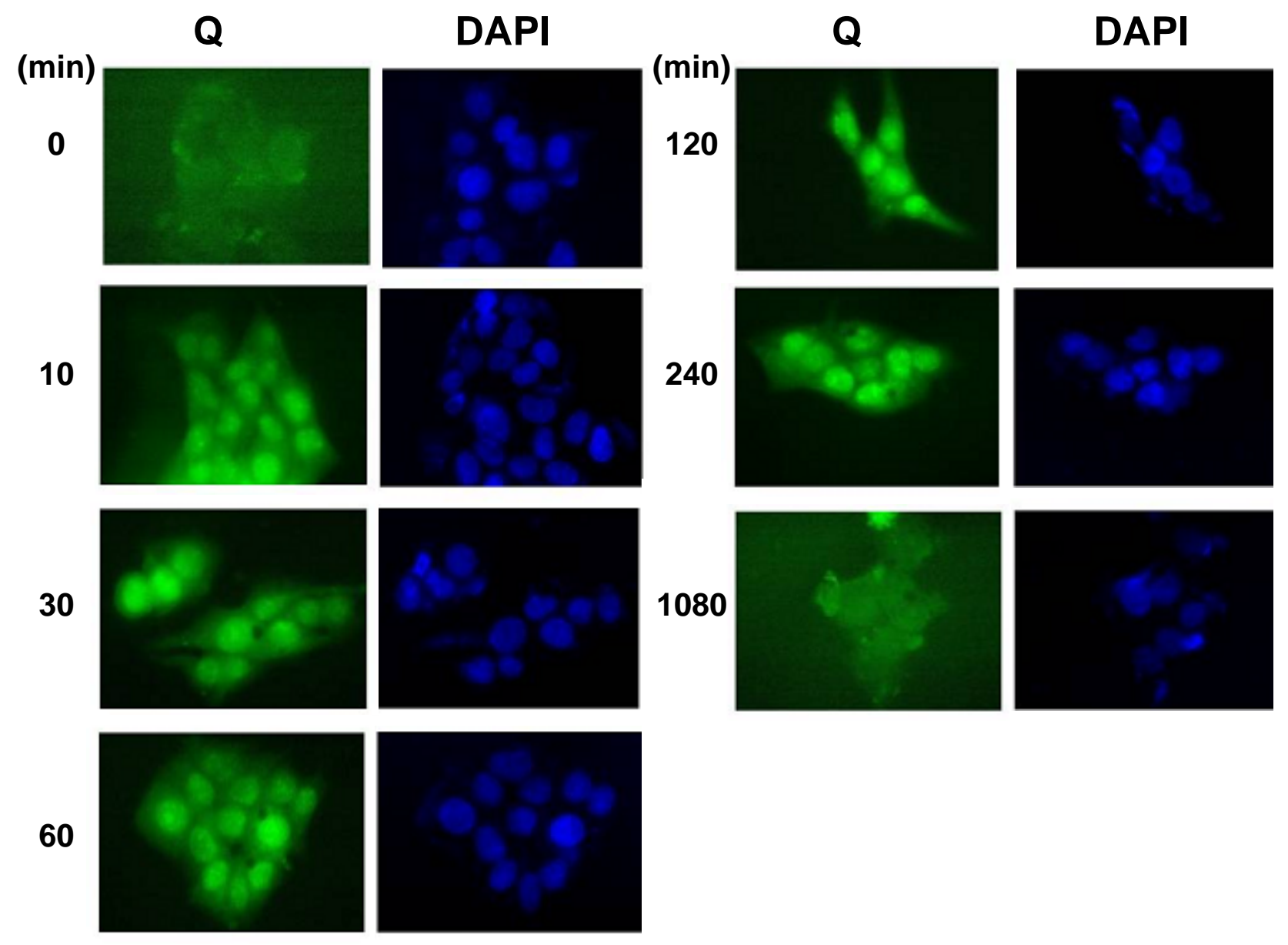


Figure 3.

A

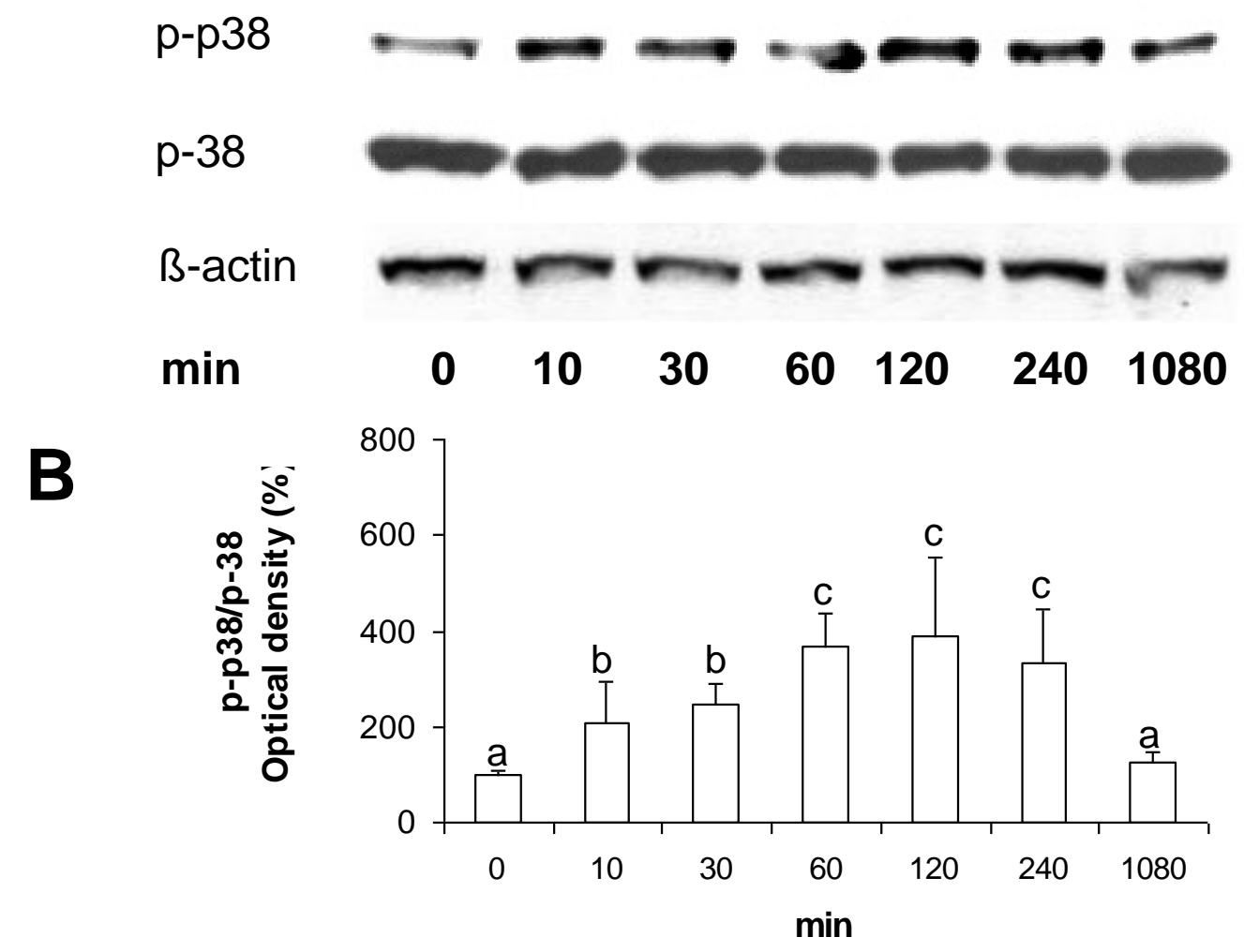


Figure 4.

A

Nrf2 (cyt, 57 kDa)

GRB2

Nrf2 (nuc, 100 kDa)

Nrf2 (nuc, 57 kDa)

PARP

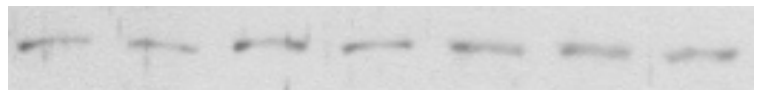

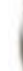

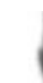

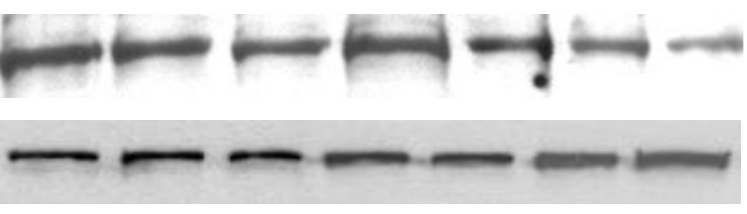

$\min$

$\begin{array}{lllllll}0 & 10 & 30 & 60 & 120 & 240 & 1080\end{array}$

B

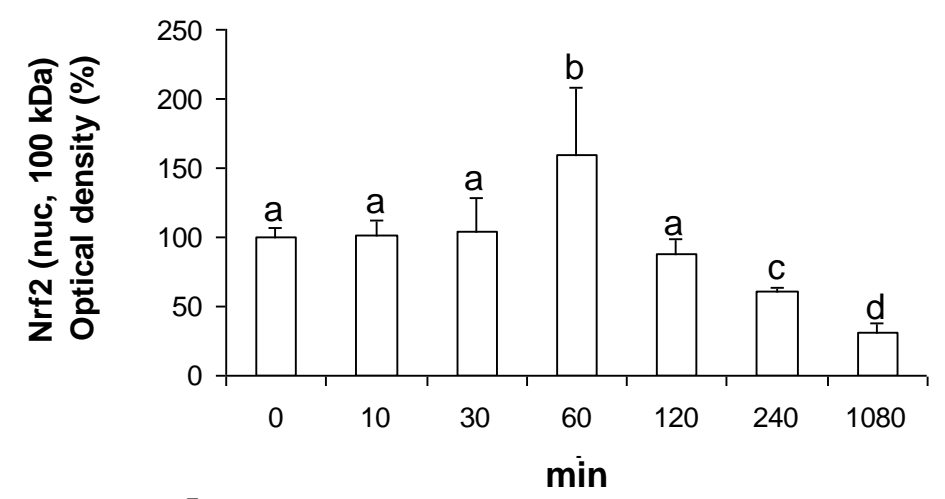

C

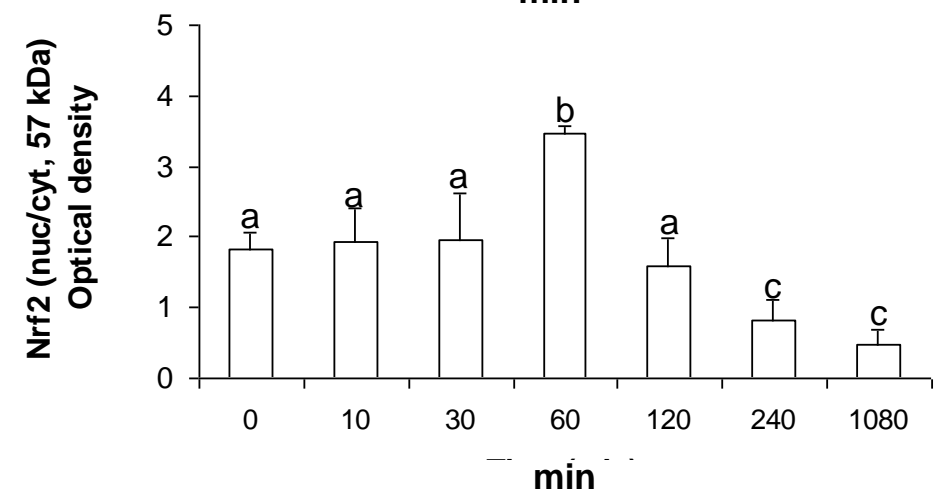

D

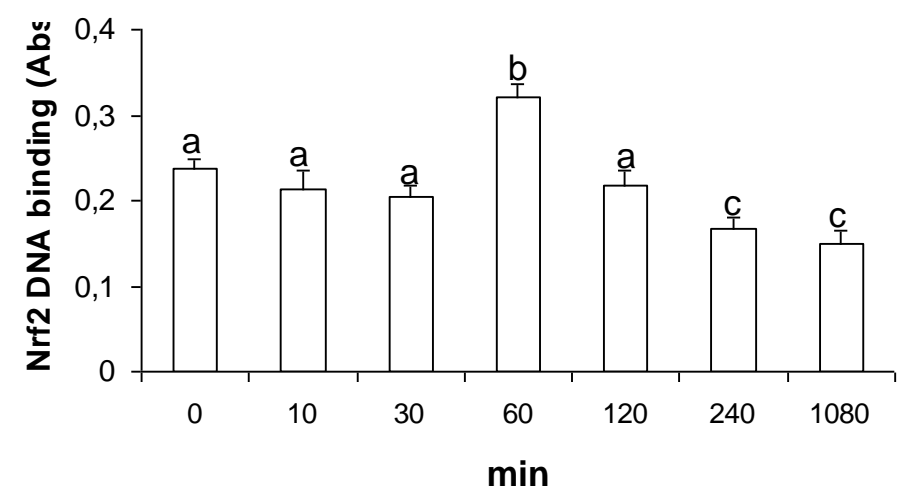




\section{Figure 5.}

\section{A}

Nrf2 (cyt, 57 kDa)

GRB2

Nrf2 (nuc, 100 kDa)

Nrf2 (nuc, $57 \mathrm{kDa}$ )

PARP
E

Nrf2 (cyt, 57 kDa)

GRB2

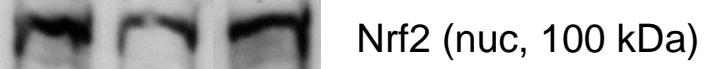

Nrf2 (nuc, 57 kDa)

PARP

$$
\text { C } \quad Q \quad Q+S B
$$
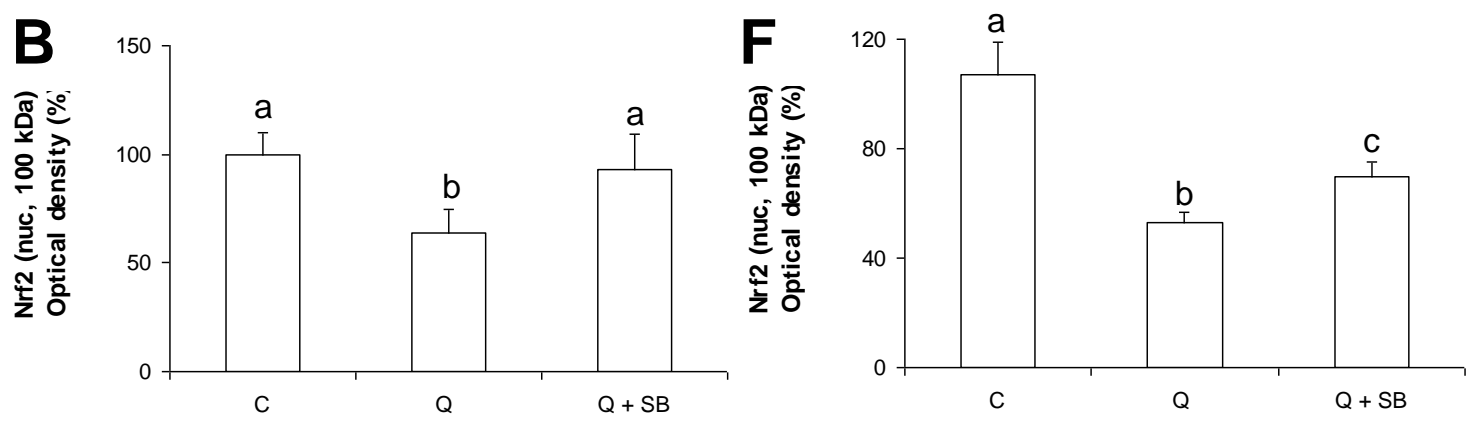

C

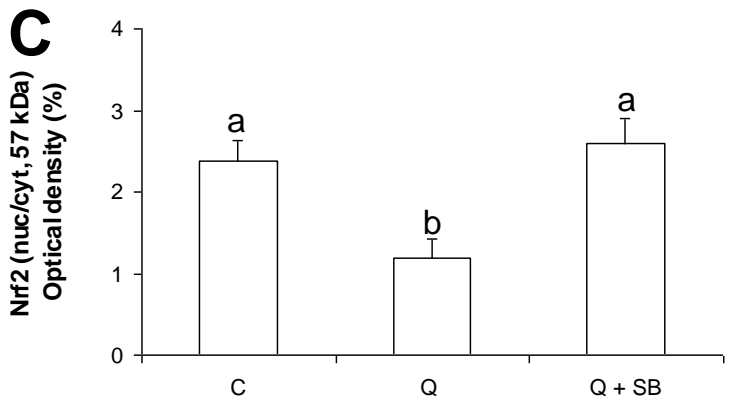

D

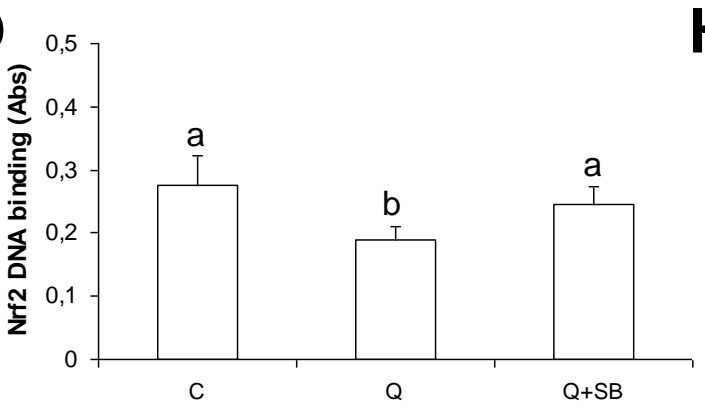

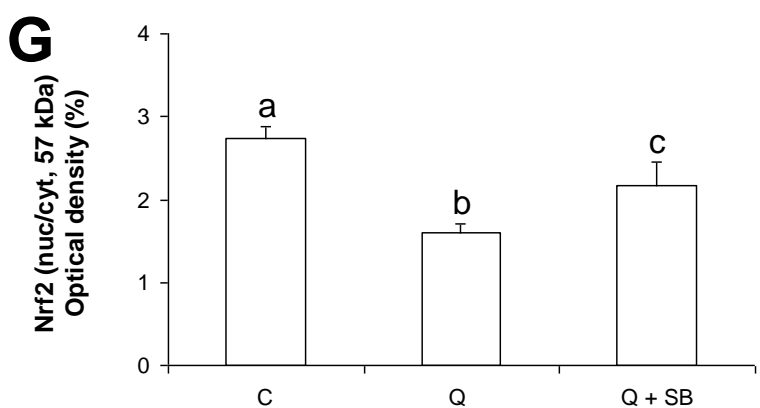

H

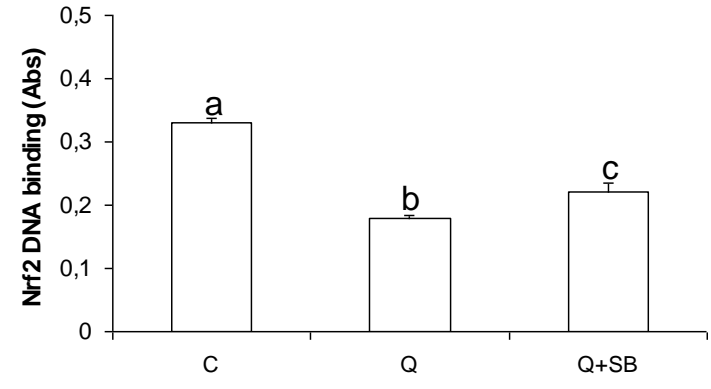


Figure 6.

A

Nrf2 (cyt, 57 kDa)

GRB2

Nrf2 (nuc, 57 kDa)

PARP
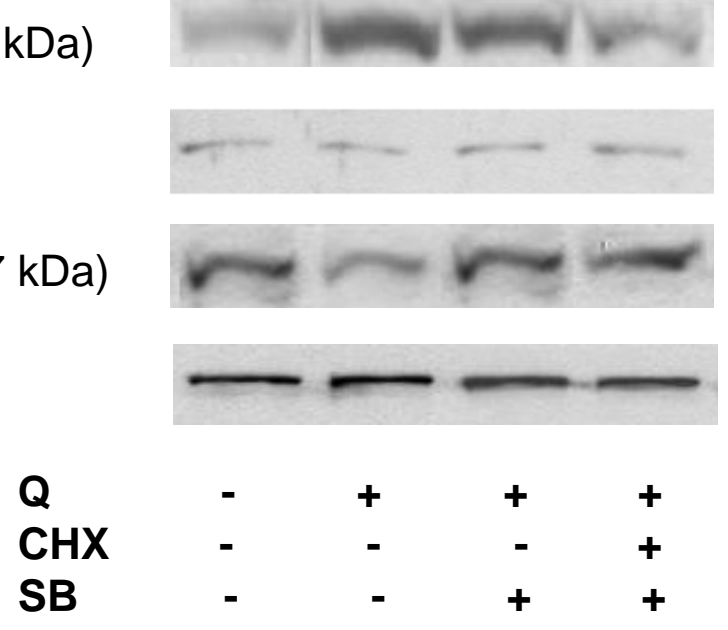

B

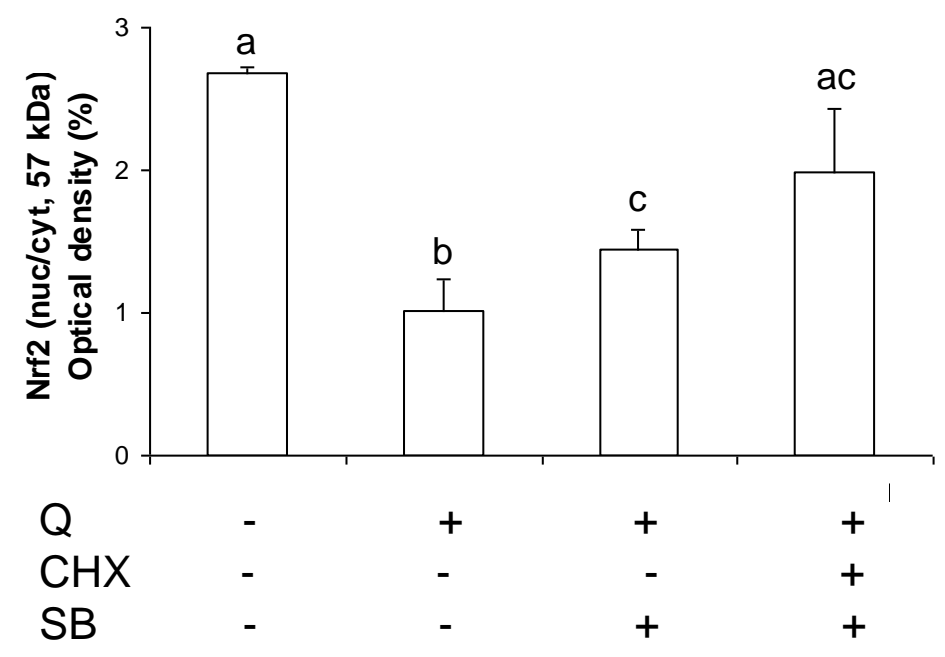


Figure 7.

A C
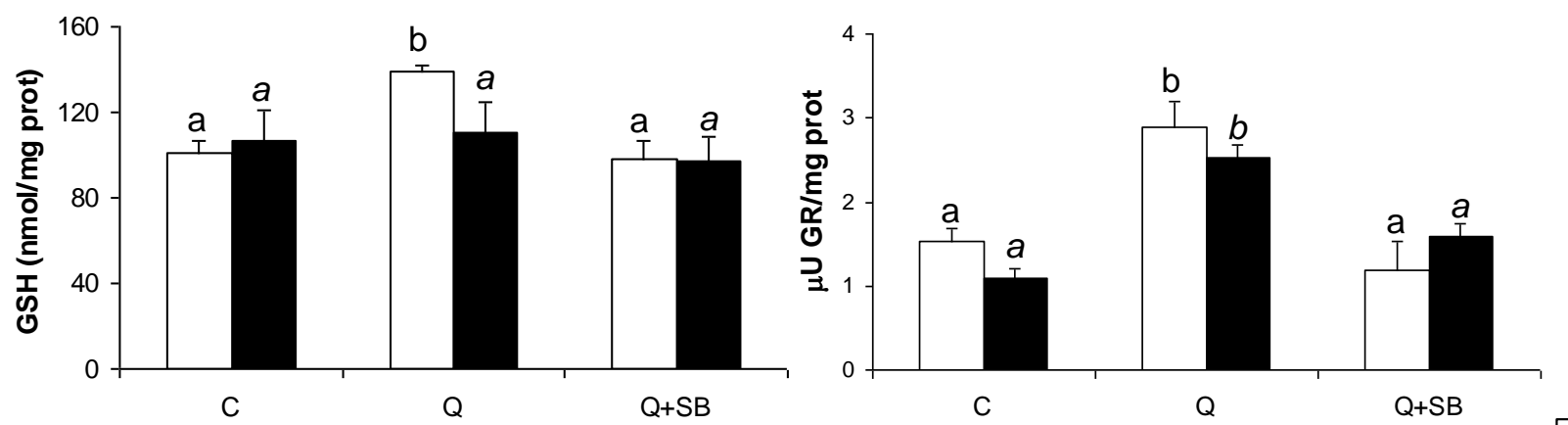

B

D
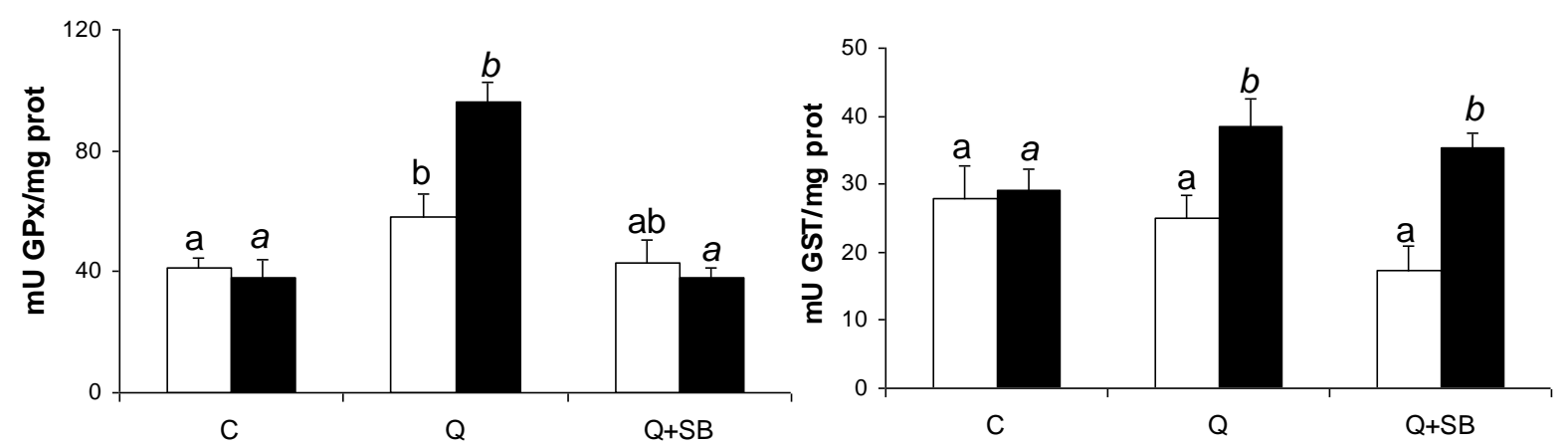
Figure 8.

A

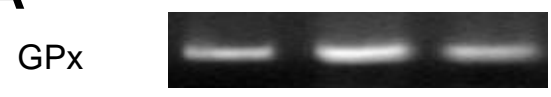

GR

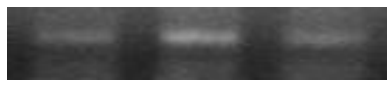

GCS

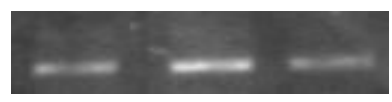

GST

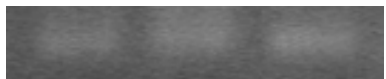

GADH

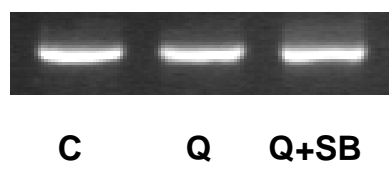

B

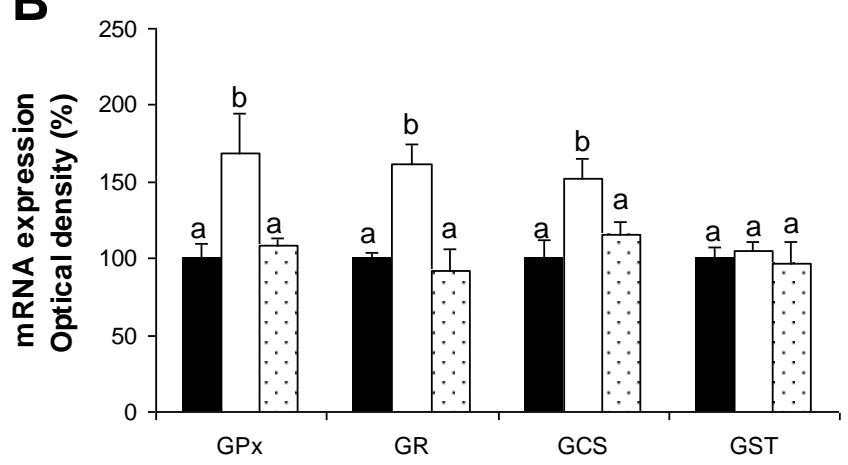

C GPx

GR

GCS

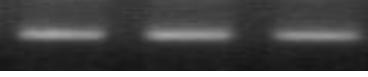

GST

GADH

C

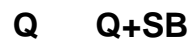

D

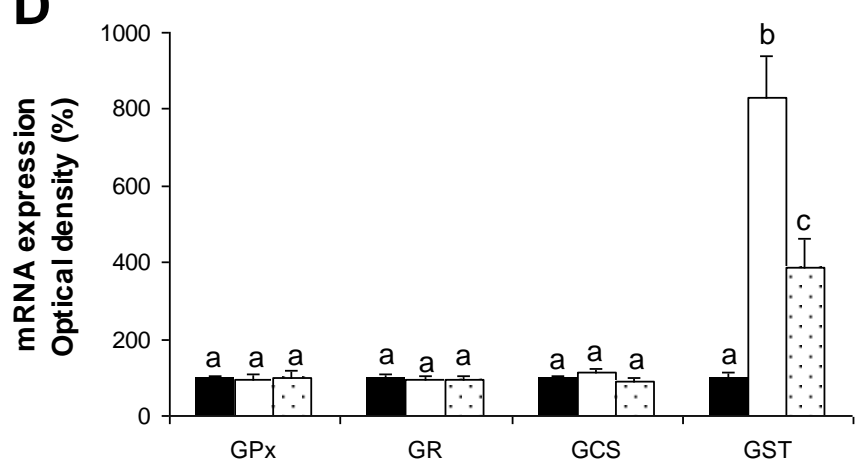

口 $\square \mathrm{Q} \boxminus \mathrm{Q}+\mathrm{SB}$ 